\title{
PENSAR A EDUCAÇÃO PROFISSIONAL A DISTÂNCIA A PARTIR DO OLHAR DO EGRESSO DO CURSO TÉCNICO EM AGROINDÚSTRIA
}

\author{
Jéssica Fernanda Hoffmann ${ }^{1}$ \\ Ricardo Lemos Sainz ${ }^{2}$ \\ Cinara Ourique do Nascimento ${ }^{3}$ \\ Veridiana Krolow Bosenbecker ${ }^{4}$
}

\begin{abstract}
Resumo: A inquietação em torno da oferta de cursos técnicos na modalidade a distância nos move à investigação de como esses cursos permitem atender àqueles estudantes que escolhem essa modalidade como possibilidade de formação. Assim, realizamos uma pesquisa com os egressos do curso Técnico em Agroindústria do Instituto Federal Sul Rio-grandense - IFSul - Campus CAVG, ofertado no polo de Santo Antônio da Patrulha. A pesquisa foi operacionalizada com um formulário do google docs. Através da metodologia do Discurso do Sujeito Coletivo - DSC, foi possível conhecer o discurso dessa coletividade, propiciando uma interlocução entre as vozes dos egressos e dos teóricos que fundamentaram o estudo. O discurso destacou a importância das aulas práticas para o aprendizado, bem como para a necessidade de ajustes e melhorias no projeto do curso.

Palavras-Chave: educação a distância, educação profissional, agroindústria, política pública.

\section{THINKING THE EAD MODE PROFESSIONAL EDUCATION IN FROM THE GRADUATES OF THE AGROINDUSTRY TECHNICAL COURSE PERSPECTIVE}

\begin{abstract}
The concern about the distance modality technical courses offer moves us to the investigation of how these courses allow to attend those students who choose this modality as a formation possibility. Thus, we conducted a survey with the graduates of the Agroindustry Technical Course of the Federal Institute South Rio-grandense - IFSul - Campus CAVG, offered in the Santo Antônio da Patrulha presencial pole. The research was operationalized with a form of google docs. Through the methodology of the Discourse of the Collective Subject - DSC, it was possible to know the discourse of this collective, favoring an interlocution between the voices of the graduates and the theorists who founded the study. The speech highlighted the importance of practical lessons for learning, as well as the need for adjustments and improvements in course design.
\end{abstract}

Keywords: distance education, professional education, agroindustry, public policy.

\section{INTRODUÇÃO}

A Educação Profissional e Tecnológica (EPT) está alicerçada na formação integral do estudante, que associa conhecimentos científicos, tecnológicos e culturais, buscando a formação de um profissional crítico e atento às políticas sociais e econômicas

\footnotetext{
1 Possui graduação em Tecnologia em Alimentos pelo Instituto Federal de Educação, Ciência e Tecnologia do Rio Grande do Sul - Campus Bento Gonçalves. Mestrado e Doutorado em Ciência e Tecnologia de Alimentos pela Universidade Federal de Pelotas.

2 Professor Titular Instituto Federal de Educação, Ciência e Tecnologia Sul-rio-grandense - IFSUL. Doutor em Ciência e Tecnologia Agroindustrial pela Universidade Federal de Pelotas. Atual na Pósgraduação Lato Sensu em Educação - Formação de professores do IFSul.

${ }^{3}$ Doutorado em Educação em Ciências pela Universidade Federal do Rio Grande - FURG. Professora Adjunta no Instituto Federal de Educação, Ciência e Tecnologia Sul-rio-grandense - IFSUL.

${ }^{4}$ Doutora em Agronomia pela Universidade Federal de Pelotas. Professora de Química do Ensino Básico,

Técnico e Tecnológico no Instituto Federal Sul-rio-grandense - Campus Pelotas.
} 
de suporte ao setor produtivo de cada região. Dessa forma, a EPT busca uma formação científica e tecnológica, na confluência de conhecimentos, saberes e competências mais abrangentes e não mecanicistas (NASCIMENTO E RODRIGUES, 2014).

O Conselho Nacional de Educação, sob o Parecer 11/2012, considera a Educação Profissional e Tecnológica (EPT) como promotora da compreensão do trabalho enquanto princípio educativo e cultural. É requerido que a EPT não promova apenas a formação de mão de obra com vista à empregabilidade imediata, mas também uma construção de conhecimentos, que possibilite ao aluno adquirir competências que possibilitem interferir no processo produtivo, compreender as formas de produção e desenvolver habilidades que capacitem o trabalhador para o exercício da reflexão, da crítica, do estudo e da criatividade (BRASIL, 2012).

Podemos dizer que a EPT pendura uma identidade que se atualiza e se reinventa a partir das múltiplas concepções que envolvem a cidadania e a realidade do mundo do trabalho, perfazendo uma trajetória que exige dar conta de um mundo multifacetado que ultrapassa o campo educacional. Além disso, nosso entendimento é de que as ações na EPT a distância são pautadas nas vivências e nos conhecimentos que não são inquestionáveis e absolutos, e, sim, alicerçados num dar-se conta que para Maturana e Varela (2011, p.32) significa um fio condutor em que "todo fazer é um conhecer e todo conhecer é um fazer".

Aliado a esse contexto e tendo em vista as políticas públicas que apoiam o desenvolvimento dos arranjos produtivos locais, bem como a inserção daqueles que se encontram distanciados dos grandes centros que detêm os locais de ensino presencial, associado à necessidade de acesso à educação destes, foi implantada, no ano de 2007 , a modalidade de Educação a Distância $(\mathrm{EaD})$ para a oferta de cursos técnicos (BRASIL, 2012).

A oferta nessa modalidade ocorre através da regulamentação do Sistema de Escola Técnica Aberta do Brasil - Rede-Tec Brasil (BRASIL, 2011) e objetiva proporcionar o aumento da oferta de vagas na EPT, ampliando a oferta de cursos técnicos de nível médio em todo o território nacional. Os cursos da Rede-Tec Brasil visam à expansão do acesso ao mundo do trabalho para jovens e adultos, à reinserção de trabalhadores e interiorização do ensino profissional. No ano de 2017, o programa de política pública Rede e-Tec Brasil comemorou dez anos de oferta de cursos técnicos na modalidade a distância, o que nos leva a pensar e a problematizar um olhar mais atento para essa modalidade de ensino que ainda nos desafia. 
Nesse cenário e aliado ao fato de que dentre as indústrias de transformação a de alimentos é a que mais se destaca no cenário socioeconômico nacional, necessitando de profissionais com domínio da ciência e tecnologia do processamento de alimentos, o Instituto Federal Sul-rio-grandense - Campus Pelotas Visconde da Graça - CAVG (IFSul-CAVG) começou a ofertar, em 2007, o Curso Técnico em Agroindústria na modalidade $\mathrm{EaD}$. Inicialmente, foram ofertadas 200 vagas distribuídas em cinco municípios do Rio Grande do Sul, que sediam polos de apoio presencial (NASCIMENTO, 2014). No ano de 2017, o curso ofertou 300 vagas distribuídas em seis polos municipais.

O Curso Técnico em Agroindústria do IFSul - CAVG, na modalidade a distância, ocorre em regime de etapa única, na forma subsequente, com carga horária de 1200 horas, com duração de dois anos (BRASIL, 2009). Ao olhar para o Projeto Político Pedagógico do curso, observa-se que é um curso que visa à capacitação, qualificação e requalificação para o desempenho das funções de Técnico em Agroindústria. A organização curricular do curso visa ao desenvolvimento de atividades teóricas e práticas (BRASIL, 2009, p. 12). O curso visa formar profissionais que atuem em indústrias de alimentos e bebidas, agroindústrias, laboratórios de controle de qualidade, e instituições de pesquisas, podendo atuar não só como profissional liberal como também empreendedor ou funcionário.

O curso de Técnico de Agroindústria é visto como fundamental para atender uma demanda crescente dos setores produtivos primários e secundários. E vem ao encontro das demandas sociais e comunitárias de profissionalização - aplicar o conhecimento tecnológico adquirido para a vivência dos chamados saberes da terra ${ }^{5}-$ geração de emprego e retomada do crescimento regional.

Com isso, a presente pesquisa evidencia a visão do egresso do curso de técnico em agroindústria na modalidade de $\mathrm{EaD}$ sobre as competências desenvolvidas durante o curso, o desdobramento para a integração do estudante no mundo do trabalho e a percepção sobre a modalidade de educação a distância. Também, alia-se, como objetivos da pesquisa, dar um retorno para as instituições em relação ao desenvolvimento de suas atividades e se as competências trabalhadas, durante o curso, contribuem para uma formação adequada de atuação no mundo do trabalho.

\footnotetext{
${ }^{5}$ Práticas tradicionais arraigadas à vivencia cotidiana do homem do campo.
} 


\section{SITUANDO O ESTUDO}

Com a finalidade de melhor atender os objetivos propostos, realizamos um estudo descritivo e exploratório de abordagem qualitativa e quantitativa, pois, nossa intenção é olhar para as abordagens de forma complementar. Entendemos que o campo de estudo em questão é relativamente novo, por isso visualizamos o uso das duas abordagens como complementariedade dos dados. Apesar de ambas as abordagens serem utilizadas de forma independente elas traduzem informações significativas entre o indivíduo singular e o coletivo. Para Minayo e Sanches (1993) na visão metodológica não há contrariedade no uso das duas abordagens, elas são, simplesmente, de naturezas diferentes.

Os egressos do Curso Técnico em Agroindústria do polo educacional de Santo Antônio da Patrulha/RS são os sujeitos desse estudo, visto que esse foi um dos primeiros polos a oferecer e a formar técnicos nessa modalidade e área de atuação. A primeira turma formada foi em 2011 e desde lá o curso formou mais quatro turmas (2012, 2013, 2014 e 2016). Para operacionalizar a pesquisa, primeiramente, foi realizado um contato com a coordenadora do polo EaD de Santo Antônio da Patrulha, que nos permitiu acesso ao cadastro dos egressos do Curso Técnico em Agroindústria formados entre os anos de 2011 a 2016, o que totalizou 83 estudantes. Posteriormente, foi criado um formulário no Google Forms com questões abertas e fechadas. Dos 83 egressos obtivemos o retorno de 15 formulários respondidos.

Num primeiro momento realizamos uma análise quantitativa que nos leva a conhecer o perfil e objetivos dos egressos com o curso. Num segundo momento, buscamos saber a opinião dos egressos sobre o curso, o que nos levou a sair da singularidade das opiniões e conhecermos o discurso dessa coletividade utilizamos a técnica do Discurso do Sujeito Coletivo - DSC de Lefèfre \& Lefèfre. O DSC é uma técnica de tabulação e organização de dados qualitativos obtidos de pensamentos, jornais, cartas, entre outros, que permite a construção do pensamento coletivo que visa revelar como as pessoas pensam, atribuem sentidos e manifestam posicionamentos sobre determinado assunto, ou seja, é o compartilhamento de ideias dentro de um grupo social (LEFÈVRE \& LEFÈVRE, 2005). O DSC é um discurso-síntese redigido na primeira pessoa do singular construído a partir de expressões chaves, das ideias centrais ou ancoragens semelhantes (LEFÈVRE \& LEFÈVRE, 2005; LEFÈVRE \& LEFÈVRE, 2006).

No DSC, as expressões chaves são entendidas como palavras ou frases que expressam a essência do conteúdo desdobrado no momento da opinião do entrevistado. 
As ideias centrais consistem no cerne, no sentido do conteúdo elaborado na coleta dos dados. Já as ancoragens nos ajudam a compreender os princípios que embasaram o discurso produzido, oferecendo a sustentação teórica.

Com isso, o DSC permitiu analisar as diferentes opiniões de forma a extrair expressões-chaves semelhantes para compor um discurso único na primeira pessoa do singular visando "dar luz ao conjunto de individualidades semânticas componentes do imaginário social” (LEFÈVRE e LEFÈVRE, 2005, p.16). Ao recebermos o retorno dos 15 egressos e analisando suas respostas foram possíveis encontrar uma recursividade no conversar que fez emergir o discurso coletivo que denominamos de: DSC 1 - "A importância do Curso Técnico em Agroindústria modalidade EaD”.

\section{O CURSO TÉCNICO DE AGROINDÚSTRIA NA MODALIDADE EAD}

A Educação a Distância6 tem uma caracterização educacional didática pedagógica de estreita relação com as Tecnologias da Informação e Comunicação TIC, direcionando a educação brasileira para um novo cenário.

Para Belloni (2008, p. 04) "[...] a EaD tende doravante a se tornar cada vez mais um elemento regular dos sistemas educativos necessários não apenas para atender a demanda e/ou a grupos específicos, mas assumindo funções de crescente importância, especialmente no ensino pós-secundário[...]” Ainda, para a autora, a EaD é um meio possível de superar os problemas educacionais emergenciais para atender às crescentes demandas por educação. As mudanças ocorridas no acesso à informação e cultura serão cada vez mais midiatizadas, bem como os processos de produção e de trabalho que reivindicam transformações nos sistemas educacionais.

A tecnologia por si só não garante a aprendizagem, é preciso o entendimento da sua importância e do compromisso como processo de ensinar e aprender, a partir de uma dimensão pedagógica e de uma correlação reflexiva dos sujeitos que interagem, desencadeando um emocionar que permita um desejo, uma vontade de aprender, numa perspectiva relacional que estabelecemos em nosso cotidiano. (NASCIMENTO, 2015, p. 39)

Precisamos pensar o processo de aprendizagem para além de um conteúdo específico, precisamos considerar o modo de relacionar nesse ambiente próprio da Ead.

\footnotetext{
${ }^{6}$ Regulamentada partir do Decreto 5.622 de 19 de Dezembro de 2005, artigo 80 da Lei de Diretrizes e Bases da Educação Brasileira (Lei 9.394 de 1996).
} 
Somente num espaço reflexivo é possível enxergar, através de inúmeras dimensões relacionais, a fim de modificar nossa visão como adultos transformadores e responsáveis pela tarefa educativa. Precisamos de um espaço reflexivo para enxergarmos por meio de inúmeras dimensões relacionais, de modo a modificar nossa visão como adultos transformadores e responsáveis pela tarefa educativa (MATURANA, D’AVILA, 2006)

No âmbito da Educação Profissional e Tecnológica, as políticas públicas passam a vislumbrar o uso das TIC, na modalidade a distância, como uma nova perspectiva educacional para o futuro. Para Moore e Kearsley (2007, p.13), o desafio da EaD também está no "[...] desenvolvimento de políticas, pelos legisladores, que ajudem as organizações educacionais a passarem de uma abordagem artesanal de ensino para uma abordagem sistêmica; [...]”. Nesse entendimento, a EaD tem sido apoiada e fomentada pelas diferentes esferas de governo, revelando, no seu acolhimento, a oportunidade de ampliação da educação. Para Pacheco, Pereira e Sobrinho (2010, p. 73), "ao romper com o projeto do governo Fernando Henrique Cardoso para a Educação Profissional e Tecnológica, o governo Lula o fez reconhecendo a importância da mesma para um desenvolvimento nacional soberano, sustentável e inclusivo [...]”.

No Instituto Federal de Ciência, Tecnologia e Educação Sul-rio-grandense IFSul/RS, a oferta dos cursos técnicos, na modalidade de EaD, ocorre desde o ano de 2007, no Campus Pelotas Visconde da Graça - CAVG7. É visível essa nova visão estratégica em torno da EPT, assegurando a sua manutenção, ampliação e, principalmente, a intencionalidade econômica e social. A oferta da Educação Profissional e Tecnológica na modalidade a distância é outra possibilidade para os que estão desassistidos pelas políticas públicas.

A oferta da educação profissional a distância inicia com dois cursos técnicos (Agroindústria e Biocombustíveis) para 5 municípios do Rio Grande do Sul que sediam polos de apoio presencial, totalizando 200 vagas no curso de Técnico de Agroindústria e 250 vagas no curso Técnico de Bicombustíveis. Nos anos seguintes, a oferta foi regular, sendo que o último processo seletivo ocorreu em janeiro de 2015 e foi ofertado no curso Técnico em Agroindústria um total de 208 vagas em cinco municípios polos do RS.

\footnotetext{
${ }^{7}$ O CAVG nessa época era ainda escola vinculada à Universidade Federal de Pelotas/RS, passando a ser
} campus do IFSul em 2010. 
Nesse cenário, o curso Técnico de Agroindústria passa a exercer uma possibilidade de profissionalização e atendimento dos arranjos produtivos locais nos municípios do interior do Rio Grande do Sul. Conforme o Projeto Político Pedagógico (BRASIL, 2009, p. 9), os objetivos específicos do curso são:

a) Desenvolver conhecimentos relacionados com os diversos setores envolvidos com a atuação técnica no âmbito da Agroindústria: planejamento, instalação, operação, controle e gerenciamento de tecnologias focadas nos princípios de produção, conservação, sustentabilidade econômica, ambiental e social.

b) Desenvolver habilidades, conhecimentos e atitudes relacionadas à ética, à normas técnicas e à segurança, necessários à produção agroindustrial.

c) Promover conhecimentos e condições estratégicas e técnicas que possibilitem desenvolver a capacidade de iniciativa, a criatividade, a tomada de decisão e o empreendedorismo.

d) Proporcionar atividades que desencadeiem o contato com ferramentas tecnológicas necessárias para atuar com base em "técnicas e tecnologias" focadas na produção e na busca de novas técnicas de produção, conservação e armazenamento agroindustrial.

Nesse sentido, o curso Técnico de Agroindústria traz uma estreita relação com o mundo do trabalho, preconizando um perfil de profissional que possa dar contar das exigências técnicas necessárias à profissão.

\section{APRESENTANDO E DISCUTINDO O ESTUDO}

A pesquisa, num primeiro momento, trouxe-nos dados quantitativos em torno do perfil do egresso. Foi possível identificar o predomínio do sexo feminino com idade de 35 anos ou mais. Isso nos permite intencionar a ascensão da mulher no mundo do trabalho no âmbito da educação profissional. Também, podemos inferir que a modalidade a distância traz uma possibilidade de educação mais ampla e democrática. A democracia é descrita, por Maturana e D’avila (2009), como um sistema político que se define como um modo de convivência em que todos os assuntos de uma comunidade são públicos e estão ao alcance para a reflexão e ação de todos os cidadãos. Ainda, para o autor, a educação a distância, quando aceita e acolhida por todos, possibilita uma modificação no 
ouvir, ver e fazer, na convivência de um país, pois permite a cooperação e a valorização do indivíduo, derrubando as barreiras culturais e econômicas.

$\mathrm{Na}$ continuidade da pesquisa, podemos olhar para os apontamentos que indicam o objetivo dos egressos ao buscar um Curso Técnico de Agroindústria na modalidade EaD. Abaixo, apresentamos a figura 1.

FIGURA 1 - Objetivos em cursar um curso profissionalizante na modalidade EaD

FONTE: os autores

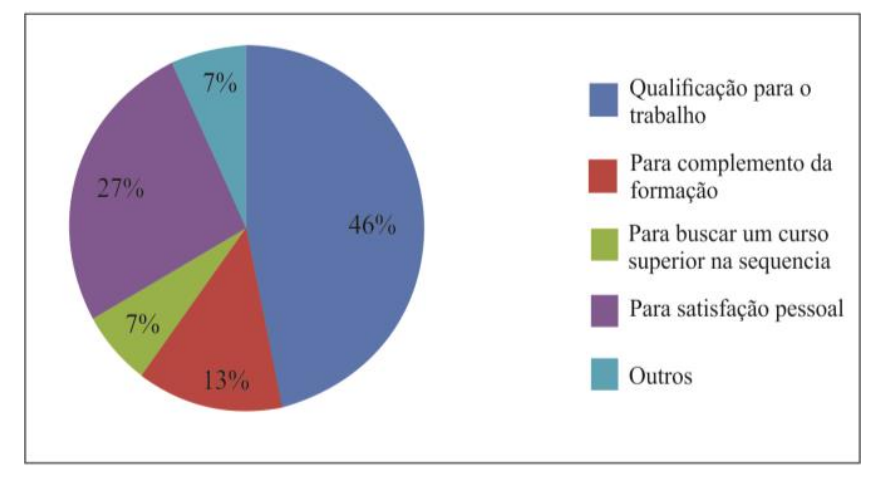

A maioria dos entrevistados (46\%) responderam que a principal finalidade de buscar um curso técnico a distância foi à qualificação para o trabalho, seguido da satisfação pessoal, num total de 27\%. Na sequência, $13 \%$ dos entrevistados responderam que o curso serviria como complemento da formação, e 7\% utilizariam o curso técnico como um elo para seguir em direção ao ensino superior.

A procura por qualificação profissional leva muitos indivíduos a optarem por cursos técnicos $\mathrm{EaD}$, por tratar-se de uma modalidade de ensino que permite a flexibilidade de horários, oportunizando ao estudante a organização e a conciliação dos estudos com outras atividades. Nas palavras de Nascimento, Rodrigues e Sainz (2014, p. 11), a oferta da educação profissional na modalidade a distância transparece o

[...] entendimento e a vontade das comunidades locais em receber cursos que promovam oportunidades de trabalho; com componentes curriculares que possibilitam a qualificação dos profissionais para geração de emprego e renda, evidenciando a necessidade de desenvolvimento desses municípios, carentes de mão de obra qualificada e/ou de melhorias nos postos de trabalho.

Os autores Quartiero, Lunardi e Bianchetti (2010) trazem o conceito de techné originário de Heródoto, como parte da palavra tecnologia, a ser entendida como um 
saber fazer eficaz, e se apoiam em Aristóteles para dizer que esse saber fazer é complexo, ou seja, um saber fazer dotado de raciocínio, de processo e de técnica. A busca pelo Curso Técnico em Agroindústria na modalidade EaD traz valoração do curso à medida que "proporciona o aproveitamento das potencialidades locais qualificando-as e contribuindo para o desenvolvimento dessas regiões8", cumprindo com o seu objetivo de promover conhecimentos que possibilitem desenvolver a criatividade, a tomada de decisão e o empreendedorismo do egresso. Assim, é possível sinalizar de forma positiva que a educação a distância pode ser transformadora à medida que possibilita o acesso da população à educação.

\subsection{O discurso dessa coletividade}

Dentro do entendimento de que o Curso Técnico de Agroindústria é essencial para atender às demandas dos setores produtivos primários e secundário, buscamos conhecer a importância dessa área de conhecimento. Da análise, emergiu o discurso denominado "A Importância do Curso Técnico em Agroindústria a distância”, o qual será apresentado a seguir:

As aulas em EAD foram ótimas. O curso tem uma base bem científica e
abrange, de forma simplificada várias áreas da agroindústria. Como eu
já trabalhava na área tinha mais facilidade para entender as matérias e é
o que as aulas práticas nos proporcionaram. A aula prática é o que
realmente nos impulsionava a continuar, o aprendizado. É onde
colocávamos em prática todo aprendizado estudado, além de interagir
com os outros polos, tutores e troca de conhecimento com outros
alunos. Porém faltam mais aulas práticas para isso. É pouca atividade
prática. Acredito que o curso de agroindústria é o alicerce para quem
quer se consolidar nesta profissão, só tem que continuar estudando.

A primeira parte do discurso que diz que "As aulas EaD foram ótimas" expressa o sentimento dos alunos em relação ao curso. Esse momento nos leva à percepção dos fundamentos do nosso emocionar, deixando nossas emoções determinarem o curso do nosso fazer. (MATURANA; VERDEN-ZÖLLER, 1998). Os egressos fazem uma reflexão que emerge da conduta emocional que busca dar sentido à experiência.

Moran (2005) fala que um bom curso depende do aluno, do professor, da direção, da instituição, da infraestrutura e dos materiais didáticos. Ainda, nas palavras do autor, "um

\footnotetext{
${ }^{8}$ BRASIL (2009). Projeto Político do Curso Técnico em Agroindústria.
} 
bom curso é aquele que nos empolga, nos surpreende, nos faz pensar, nos envolve ativamente, traz contribuições significativas e nos põe em contato com pessoas, experiências e ideias interessantes" (p. s/n). Podemos dizer que destaca o potencial da EaD e o quanto essa modalidade de ensino pode fazer a diferença na vida pessoal e profissional daqueles que a vivenciam. Ela amplia o acesso à educação daqueles que estão longe dos bancos regulares, possibilitando a formação e a qualificação de profissionais, o desenvolvimento de competências complexas como autonomia, autoestudo9, autoavaliação, administração do tempo e autogestão da carreira (ABBAD, 2007).

Outro fragmento do discurso mostra que os alunos consideram que "o curso apresenta uma base científica abrangente". Essa parte do discurso mostra que o projeto político pedagógico do curso é bem atendido, pois visa à formação de profissionais técnicos capazes de aliar o conhecimento da ciência, da técnica e da tecnologia aos processos de transformação e conservação de alimentos (PPC, p. 9). A abrangência da Educação Profissional e Tecnológica vai além da formação de mão de obra. O parecer da CNE 11/2012 diz que é inadmissível que o profissional de hoje atue apenas de maneira mecânica, é "necessário que o trabalhador tenha conhecimento da tecnologia, da ciência e dos processos necessários em sua produção. A escola especializada ou voltada para a formação profissional deve atentar para essa necessidade" (BRASIL, 2012). Nesse sentido, o Curso Técnico em Agroindústria na modalidade EaD atende a esses requisitos, proporcionando aos egressos uma visão ampla e científica de todo o processo produtivo.

No discurso, é observado que o conteúdo do curso fica mais acessível àqueles que já trabalhavam na área. Quando a teoria e prática se confrontam, o estudante se torna um pensante ativo, nesse momento, constrói/reconstrói o conhecimento (DEMO, 2007). Bizzo (2000) também nos diz que a vivência da prática é importante para o aluno, porque, muitas, vezes ele tem dificuldade de compreender o porquê dos conteúdos estudados em sala de aula.

Em relação às aulas práticas, a visão dos alunos é que “A aula prática é o que realmente nos impulsionava a continuar, o aprendizado. É onde colocávamos em prática todo aprendizado estudado, além de interagir com os outros polos, tutores e troca de conhecimento com outros alunos". Nesse trecho, é destacada a importância dada às aulas práticas no desenvolvimento do curso e dos alunos. Na visão de Nascimento (2015), a motivação das aulas práticas são um elemento de reflexão para a revisão dos

\footnotetext{
${ }^{9}$ Estudo realizado de forma autônoma, sem necessidade de professor.
} 
projetos pedagógicos do curso. É possível dizer que a aula prática permite e/ou dá condições de aproximação do aluno do seu fazer.

As aulas práticas também permitem que o aluno vivencie o método científico, já que despertam e mantêm o interesse dos alunos; envolvem os estudantes em investigações científicas; desenvolvem a capacidade de resolver problemas; compreendem conceitos básicos; e desenvolvem habilidades. (KRASILCHIK, 2008). Na visão de Nascimento (2015, p. 83) “A motivação através das aulas práticas torna-se um importante elemento de reflexão para construção e revisão dos projetos pedagógicos de cursos. Podemos dizer que a aula prática permite e/ou dá condições de aproximação do aluno do seu fazer".

Com esse entendimento, a Secretaria de Educação Profissional e Tecnológica SETEC viabilizou a criação de laboratórios móveis montados em caminhões, atendendo às especificidades de cada curso, com a finalidade de sanar a problemática da ida dos alunos às instituições de ensino ou às indústrias relacionadas com as áreas do conhecimento de cada curso e, assim, atender o que preconiza o parecer da CNE/CEB $11 / 2012$, ao reafirmar que a oferta na modalidade a distância deve seguir as mesmas orientações da forma presencial, ou seja, “ambas se orientam pelo Catálogo de Cursos Técnicos de Nível Médio, realizam acompanhamento pedagógico, práticas em laboratórios, oficinas, [...]" (p.54).

$\mathrm{Na}$ figura 2, podemos visualizar o Laboratório Móvel disponibilizado pela Secretaria de Educação Profissional e Tecnológica - SETEC/MEC.

FIGURA 2 - Laboratório Móvel

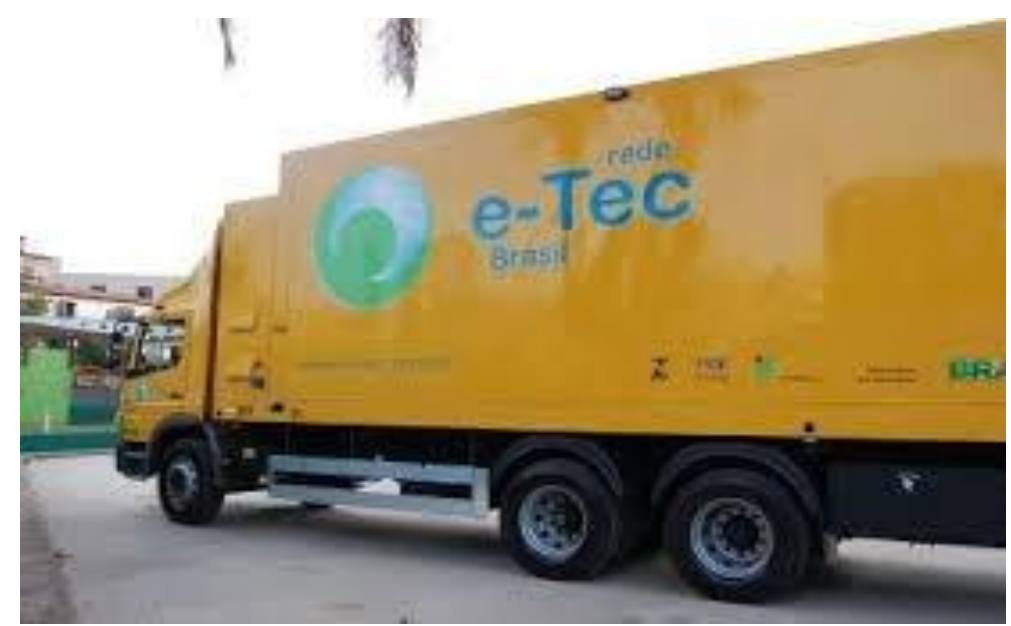

FONTE: acervo e-Tec IFSul/CAVG 
No entanto, até o momento, esse laboratório ainda não foi utilizado, pois, segundo a coordenação do curso, o mesmo não se encontra em condições de uso por vários problemas técnicos apresentados.

No discurso, observa-se a importância dos encontros presenciais, pois possibilitavam a maior interação entre alunos, professores, tutores. A legislação preconiza que se tenham encontros presenciais para as aulas práticas e atividades avaliativas (BRASIL, 2012). Ainda em relação às aulas práticas, o sentimento dos egressos é que "faltam aulas práticas". Esse foi o mesmo sentimento observado por Nascimento e Rodrigues (2014) ao avaliarem os discursos das coordenadoras de polos de EaD. Naquele trabalho, as autoras sugerem que as aulas práticas são um

\begin{abstract}
Balizador de ações futuras dos institutos que pretendem oferecer Educação Profissional e Tecnológica, na modalidade à distância, diz respeito ao desenvolvimento pleno dos cursos envolvendo tanto a parte teórica quanto a prática. As coordenadoras de polo destacam que sentem "falta de aulas práticas mais frequentes, os alunos desistiriam em menor número, pois as aulas práticas motivam imensamente aos alunos". Suas falas refletem uma das tantas dificuldades que são encontradas na implantação de cursos técnicos a distância, evidenciando a necessidade de soluções efetivas nesse sentido" (NASCIMENTO E RODRIGUES, 2014, p. 166).
\end{abstract}

O discurso coletivo evidencia a necessidade de revisar a quantidade de aulas práticas realizadas. A legislação preconiza que de $20 \%$ a $50 \%$ do curso seja realizado de forma presencial, justamente para o desenvolvimento de aulas práticas e atividades avaliativas (BRASIL, 2012). Dessa forma, sinaliza que é necessária a revisão constante do projeto do curso, visando atender o desejo da comunidade acadêmica e os anseios e necessidades econômicas e sociais. É claro que, para que esse fato seja atendido, é preciso ver se a instituição apresenta infraestrutura adequada para a realização de mais atividades práticas.

Nascimento, Rodrigues e Sainz (2017) propõem que sejam implantadas diferentes ferramentas para suprir a carência de aulas práticas nos cursos técnicos a distância, porquanto, mesmo que sejam utilizados "vídeos, práticas dirigidas a distância nos polos, e visitas técnicas, possibilitando que alunos tivessem contato com a fábrica e a pequena indústria, parece não ter sido suficientes para atender os anseios e desejos dessa comunidade".

O último aspecto a ser observado no discurso é que o curso técnico é considerado um "abre porteiras" para a qualificação profissional, mas não pode ser o 
final da linha, é preciso "continuar estudando". Esse discurso destaca a necessidade de atualização e qualificação constante.

\section{CONSIDERAÇÕES FINAIS}

A importância do contexto regional na formação dos estudantes encontra respaldo na compreensão de que os cursos devem buscar atender aos arranjos produtivos locais, como forma de desenvolvimento econômico e social e de permanência dos jovens em seus locais de origem, indo ao encontro da filosofia dos Institutos Federais de Educação, Ciência e Tecnologia. Nesse sentido, a modalidade de $\mathrm{EaD}$ oferece possibilidades efetivas de disseminação e alcance daqueles estudantes que se encontram fora dos bancos escolares regulares. O estudo resulta num conhecer que dá voz e produz um sentido para o desenvolvimento da Educação Profissional e Tecnológica a distância. É nas interações recorrentes que nos mantemos vivos, numa dinâmica relacional com o mundo e com seus significados (MATURANA, 1993).

O discurso dos egressos demonstrou que o curso Técnico em Agroindústria na modalidade a distância apresentou uma base científica abrangente e que as aulas foram consideradas boas. Os alunos egressos descreveram a importância das aulas práticas para o aprendizado, pois, segundo eles, era o que os impulsionava a continuar, já que, naquele momento, ocorria o compartilhamento de conhecimento com os outros alunos ou tutores. Esse discurso sinalizou a necessidade de ajustes e melhorias, principalmente no quesito aulas práticas.

Ouvir os alunos egressos nos leva a problematizar e a traçar considerações na busca constante pela melhoria da Educação Profissional e Tecnológica. Dessa forma, sugere-se que o projeto político pedagógico dos cursos seja constantemente revisado de forma a atender às expectativas dos alunos e da sociedade. Nas palavras de Nascimento, Rodrigues e Sainz (2017), as políticas públicas devem considerar que a oferta dos cursos técnicos a distância são possibilidades efetivas de inserção no mercado de trabalho, logo devem apoiar uma configuração de um projeto político-pedagógico capaz de atender às especificidades dessa modalidade.

No entendimento das restrições intrínsecas a qualquer pesquisa, em função de método e do número de sujeitos pesquisados, sugerimos que os resultados aqui apresentados possam ser aprofundados em novos estudos sobre a temática. Como essa pesquisa foi realizada apenas com alunos egressos do polo de Santo Antônio da Patrulha, 
seria interessante conhecer a realidade de formação e de atuação profissional dos alunos formados em outros polos educacionais, o que possibilitaria uma visão mais ampla da oferta do curso na modalidade EaD e de como ele articula com o mundo do trabalho.

Recebido em: 12-01-2018 Aceito em: 21-06-2018

\section{REFERÊNCIAS}

ABBAD, G. S. Educação a distância: o estado da arte e o futuro necessário. Revista do Serviço Público Brasília, v. 58, n. 3, p. 351 - 374, 2007.

BELLONI, Maria Luiza. Educação a Distância. Campinas, SP: Autores Associados, 2008.

BIZZO, N. Ciências: fácil ou difícil? São Paulo: Ática, 2000.

BRASIL. 2005. Presidência da república. Decreto no 5622/2005 (de 19 de dezembro de 2005. Disponível em <http://www.planalto.gov.br/ccivil_03/_ato20042006/2005/decreto/d5622.htm>. Acesso em 05 abr 2016.

BRASIL. 2009. Instituto Federal de Educação, Ciência e Tecnologia Sul-riograndense. Projeto Pedagógico do Curso Técnico em Agroindústria - forma subsequente Modalidade EaD.2009. Disponível em:

<http://portal2.ifsul.edu.br/index.php?option=com_docman\&task=doc_download\&gid= 1519\&Itemid=3>. Acesso: 22 abr 2017.

BRASIL. 2011. Presidência da República. Decreto $n^{\circ} 7.589$, de 26 de outubro de 2011. Disponível em: <http://www.planalto.gov.br/ccivil_03/_Ato20112014/2011/Decreto/D7589.htm\#art9>. Acesso em 04 abr 2016.

BRASIL. Ministério da Educação. Parecer CNE/CEB no 11/2012. Disponível em: <http://portal.mec.gov.br/index.php?option=com_content\&id=17576\&Itemid=866> Acesso em 04 abr 2016.

BRASIL. 2017a. Instituto Federal de Educação, Ciência e Tecnologia Sul-rio-grandense. e-Tec CAVG - Cursos técnicos CAVG. Disponível em: <http://ead.ifsul.edu.br/index.php/e-tec-cavg>. Acesso 22 abr 2017.

BRASIL. 2017b. Instituto Federal de Educação, Ciência e Tecnologia Sul-rio-grandense IFSUL/CAVG. Catálogo de Cursos: Técnico em Agroindústria modalidade à distância. Disponível em: <http://portal2.ifsul.edu.br/proen/site/catalogo_curso.php?cod=75>. Acesso em 04 abr 2017.

DEMO, Pedro. Educar pela pesquisa. 8. ed. Campinas: Autores Associados, 2007.

KRASILCHIK, M. Prática de Ensino de Biologia. São Paulo: Edusp, 2008. 
LEFÈVRE, F.; LEFÈVRE, A. M. C. Discurso do Sujeito Coletivo: um enfoque em pesquisa qualitativa (desdobramentos). Editora da Universidade de Caxias do Sul. 256p, 2005.

LEFÈVRE, F.; LEFÈVRE, A. M. C. O sujeito coletivo que fala. Interface Comunicação, saúde e educação, v. 10, n. 20, p. 517-524, 2006.

MATURANA, Humberto R; VERDEN-ZÖLLER, Gerda Verden. Amar e Brincar Fundamentos esquecidos do humano. Palas Athena, São Paulo, 1998.

MATURANA, Humberto R; DÁVILLA, Ximena Paz. Educação a partir da matriz biológica da existência humana. Revista Prelac, n.2, Chile, 2006.

MATURANA, Humberto R; DÁVILA, Ximena Yáñez. Habitar humano em seis ensaios de biologia-cultural. São Paulo: Palas Athena, 2009.

MATURANA, H; VARELA. F. Árvore do Conhecimento: as bases biológicas da compreensão humana. 9 ed. São Paulo: Palas Athenas, 2011.

MATURANA, Humberto R; Uma nova concepção de aprendizagem. Revista Dois Pontos. Belo Horizonte, v.2, n.15, p. 28-35, 1993.

MINAYO, M. C. S. \& SANCHES, O. Quantitativo-Qualitativo: Oposição ou Complementaridade? Cad. Saúde Públ., Rio de Janeiro, 9 (3): 239-262, jul/set, 1993.

MOORE, Michel G; KEARSLEY, Greg. Educação a Distância - uma visão integrada. Tradução de: Roberto Galman. São Paulo: Thomson Learning, 2007.

MORAN, J. M. O que é um bom curso a distância? Disponível em: <http://www.eca.usp.br/prof/moran/site/textos/educacao_online/bom_curso.pdf >. Acesso em 27 mai 2017.

NASCIMENTO, C. O. O engendramento coletivo da educação profissional e tecnológica a distância: histórias que contam as experiências dos polos de apoio presencial. 2015. 105f. Tese (Programa de Pós-Graduação em Educação em Ciências: Química da Vida e Saúde) - Universidade Federal do Rio Grande, 2015.

NASCIMENTO, C. O.; RODRIGUES, S. C. A educação a distância como oportunidade de formação profissional e tecnológica. RIED. Revista Iberoamericana de Educación a Distancia, v. 17, n. 2, p. 151-171, 2014. Disponível em: <http://revistas.uned.es/index.php/ried/article/viewFile/12682/11876> Acesso em 30 mai 2016

NASCIMENTO, C. O.; RODRIGUES, S.C.; SAINZ, R.L. A Educação a distância como política púbica no ensino profissional e tecnológico: experiência do IFSul/CaVG. In: IV Congresso Ibero Americano de Política e Administração da Educação / VII Congresso luso Brasileiro de Política e Administraçao da Educacao, 2014, Porto / Portugal. Políticas e práticas de Administracao e Avaliacao na Educacsao Ibero Americana. Porto/Portugal: Cadernos ANPAE, 2014. v. 1. p. 1-14. Disponível em: 
http://www.anpae.org.br/IBERO_AMERICANO_IV/GT3/GT3_Coimunicacao/Cinara OuriqueNascimento_GT3_integral.pdf Acesso 30 mai 2016.

NASCIMENTO, C. O.; RODRIGUES, S.C.; SAINZ, R.L. Desdobramentos constitutivos do curso técnico de agroindústria na modalidade a distância. Tecnologia Educacional, 2017. Artigo aceito para publicação.

PACHECO, Eliezer Moreira; PEREIRA, Luiz Augusto Caldas; SOBRINHO, Moisés Domingos. Institutos Federais de Educação, Ciência e Tecnologia: limites e possibilidades. Revista Linhas Críticas, Brasília, DF, v. 16, n. 30, p. 71-88, 2010. Disponível em: <periodicos.unb.br/índex.php/linhascriticas/issue/view/174>. Acesso em: 24 ago. 2017.

QUARTIERO, Elisa Maria; LUNARDI, Geovana Mendonça; BIANCHETTI, Lucídio. Técnica e tecnologia: aspectos conceituais e implicações educacionais. In: MOLL, Jaqueline (org.). Educação Profissional e Tecnológica no Brasil Contemporâneo, Porto Alegre, Artmed, 2010, p. 285-300. 